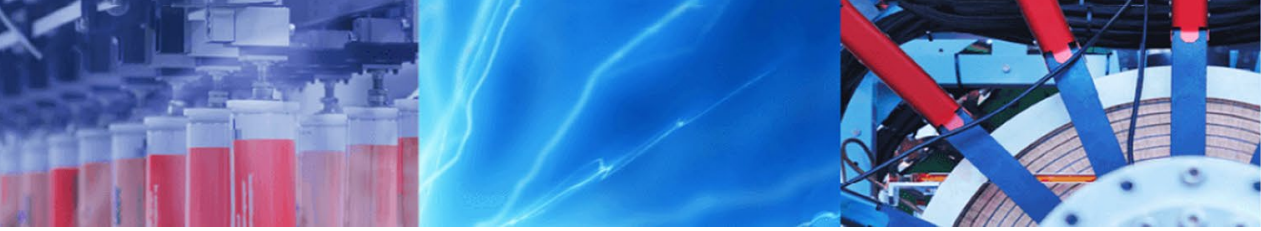

Short Communication

\title{
Structural and chemical comparison between moderately oxygenated and edge oxygenated graphene: mechanical, electrical and thermal performance of the epoxy nanocomposites
}

\author{
Orestis Vryonis $^{1}$ (D) . Thomas Andritsch ${ }^{1}$ (D) Alun S. Vaughan ${ }^{1}$ (D) Paul L. Lewin $^{1}$ (D)
}

(C) The Author(s) 2019 OPEN

\begin{abstract}
Two different graphitic powders, namely: moderately-oxidized graphene oxide (mGO) synthesized via a chromium-based technique and a commercial edge-oxidized graphene oxide (eGO), were characterized and incorporated into an epoxy resin, suitable for wind turbine blade structural components. Raman spectroscopy, X-ray photoelectron spectroscopy and thermogravimetric analysis revealed low oxygen content, but divergent structural characteristics for both powders confirming the increased basal-plane functionality of $\mathrm{mGO}$ compared to the peripherally decorated eGO. It is also shown that the eGO, displays carbon-based impurities. The inclusion of $\mathrm{mGO}$, into the epoxy resulted in an initial glass transition temperature $\left(T_{g}\right)$ increase $\left(\sim 5^{\circ} \mathrm{C}\right.$ at $\left.4.4 \mathrm{vol} . \% \mathrm{mGO}\right)$ but thereafter $T_{g}$ decreased sharply. On the contrary, the inclusion of eGO resulted only in a progressive $T_{g}$ increase. Introduction of just 1 vol.\% of eGO deteriorated the tensile strength ( $15 \%$ reduction) of the epoxy, while the strength of the $\mathrm{mGO}$-filled samples was retained. Inclusion of mGO results in a percolation threshold (increase from $4.6 \times 10^{-16}$ to $6 \times 10^{-9} \mathrm{~S} / \mathrm{cm}$ ) at $0.53 \mathrm{vol} . \%$; in contrast, at the same filler content, the eGO-filled systems are characterized by drastically lower conductivity values $\left(3.4 \times 10^{-16} \mathrm{~S} / \mathrm{cm}\right)$. Nevertheless, further analysis indicates similar intrinsic conductivity $\left(\sim 10^{-6} \mathrm{~S} / \mathrm{cm}\right)$ for the two fillers. Finally, the maximum achieved thermal conductivity increase with $\mathrm{mGO}$ was $200 \%$ (at 9.13 vol.\%) compared with the unfilled epoxy, while the respective increase with eGO was $150 \%$ (at 18 vol.\%).
\end{abstract}

Keywords Graphene · Moderate oxidation · Edge oxidation · Surface chemistry · Epoxy composites

\section{Introduction}

Composite materials based upon a particulate, platelet or fibrillar phase dispersed within a polymeric matrix are used in many different application areas [1, 2]. For example, the dispersion of organoclays within polymers can improve fire retardancy [3], while conductive (electrically and/or thermally) fillers can be used in a number of applications [4], such as: conductive adhesives, EMI shielding, static charge and/or heat dissipation, as well as modifying the electric field distributions in power cables [5], etc. Indeed, many studies have been undertaken with a view to enhancing the mechanical, electrical and thermal performance of polymeric matrices through the incorporation of carbonaceous fillers, such as carbon black [6], expanded graphite (EG) [7] and carbon nanotubes [8]. The nanometric equivalent of graphite is graphene and, by appropriate treatment, graphite can be converted into graphene nanoplatelets (GNP) [9] or graphene oxide (GO) [10] and, thereby, utilized as a polymer nanofiller. EG and subsequently GNP are traditionally processed by acidic intercalation of the graphite followed by thermal shock, a process that slightly oxidizes the graphitic layer edges [11]. Conversely, GO exhibits markedly increased oxygen

Orestis Vryonis, O.Vryonis@soton.ac.uk; Thomas Andritsch, T.Andritsch@soton.ac.uk; Alun S.Vaughan, asv@ecs.soton.ac.uk; Paul L. Lewin, pll@ecs.soton.ac.uk| ${ }^{1}$ Tony Davies High Voltage Laboratory, Department of Electronics and Computer Science, Faculty of Engineering and Physical Sciences, University of Southampton, Southampton, UK.

SN Applied Sciences (2019) 1:1275 | https://doi.org/10.1007/s42452-019-1303-9

Received: 31 May 2019 / Accepted: 18 September 2019 / Published online: 25 September 2019 
content [12], due to the oxidation occurring through exposure to strong oxidants, such as potassium permanganate $\left(\mathrm{KMnO}_{4}\right)$. Considering the commonly used Lerf-Klinowski model [13], GNP contain carboxyl groups attached on the edges (thus, alternatively called edge-oxizidized graphene, eGO), while GO would additionally display hydroxyl and epoxide groups on the basal surfaces. The presence of such functional groups can provide several attributes, such as enhanced dispersion within polar solvents/polymers [14], or be exploited as reactive sites for further surface functionalization [15]. However, such chemical modifications also equate to structural defects, which can result in impaired electrical [16] and thermal [17] transport and may even perturb the reaction stoichiometry when incorporated into epoxy resins [18]. The consequence of such processes can be sub-optimal system properties.

Properly engineered/treated graphitic materials will potentially lead to nanocomposite epoxy systems with low electrical percolation thresholds, enhanced thermal conductivity and non-compromised mechanical performance or stoichiometry. Such systems could provide alternative material solutions to the costly and hazardous [19] CNT systems. Possible industrial applications are in carbon fibre-based wind turbine blades [20], where (electrically and thermally) conductive interfaces and/or binding thermosets are needed for lightning protection coordination [21]. Elsewhere, enhanced ability to resist lightning strikes is of enormous importance in the aerospace industry [22], as manufacturers increasingly turn towards carbon fibre composites for aircraft construction [23].

From the above account, it is evident that optimisation of the overall property envelope of graphite-based composite systems requires careful tailoring of both structural and chemical factors. Consequently, many studies have sought to address this issue by altering the oxygen content of graphene through various modifications of conventional synthesis routes $[24,25]$, by changing the precursor graphite's lateral size [26] or through novel processing methodologies, such as electrochemical exfoliation [27]. In a previous publication [28], we reported on an alternative synthetic route for the production of graphene oxide in which the commonly used $\mathrm{KMnO}_{4}$ oxidant was replaced with chromium trioxide $\left(\mathrm{CrO}_{3}\right)$. The consequence was a reduced degree of oxidation and, as such, the product was termed moderately oxidized graphene oxide ( $\mathrm{mGO}$ ). This system could effectively be introduced without any further treatment into epoxy matrices, for electrical and thermal enhancements, similarly to the eGO systems mentioned above. The work reported here, therefore, sets out to compare the properties of epoxy nanocomposites based upon $\mathrm{mGO}$ and commercially available $\mathrm{eGO}$ and, specifically, to determine the structure/property relations between the respective graphitic surface chemistries.

\section{Experimental}

Graphite, sulfuric acid $\left(\mathrm{H}_{2} \mathrm{SO}_{4}\right)$ and hydrogen peroxide solution (35\%) were obtained from Sigma Aldrich (496596, 435589 and 349887, respectively). Chromium (VI) trioxide $\left(\mathrm{CrO}_{3}\right)$ was purchased from Fischer scientific (11390939). The epoxy resin was supplied by LEUNA-Harze GmbH (EPI-

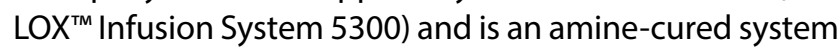
designed for use in structural fibre reinforced composites for wind energy applications. The two constituents are: $E R$ 5300 (a DGEBA-based resin-epoxy equivalent weight: $170 \mathrm{~g} / \mathrm{eq}$ ) and EC 5310 (amine value: $520 \mathrm{mg} \mathrm{KOH} / \mathrm{g}$ ) as monomer and hardener components, respectively. The system was formerly produced and supplied by BASF, The Chemical Company, under the name Baxxodur system 5300. Edge oxidized graphene powder was supplied by Garmor Inc. Moderately oxidized graphene was synthesized via an oxidation process involving a solution of $\mathrm{CrO}_{3}$ in $\mathrm{H}_{2} \mathrm{SO}_{4}$, as described previously [28].

The initial stage in the preparation of epoxy-based composites involved the dispersion of the required quantity of filler within the epoxy resin using a planetary mixer (Speedmixer ${ }^{\mathrm{TM}}$ DAC $150.1 \mathrm{FV}$ ) operating at $3000 \mathrm{rpm}$ for 5 min. Afterwards, the hardener was added (10:2 epoxy/ hardener mass ratio, as suggested by the supplier) and the mixture was vacuum degassed. Finally, the mixture was cast into appropriately shaped moulds and cured at $70^{\circ} \mathrm{C}$ for $6 \mathrm{~h}$, again, as suggested by the epoxy manufacturer.

The eGO and mGO powders were characterized by Raman spectroscopy (Renishaw RM1000 confocal microprobe, $780 \mathrm{~nm}, 2.5 \mathrm{~mW}), \mathrm{X}$-ray photoelectron spectroscopy (XPS-Kratos Axis Ultra DLD; AI Ka X-ray source, pass energy $20 \mathrm{eV}$ for core-level spectra) and thermogravimetric analysis (TGA-Perkin-Elmer Pyris 1, $10^{\circ} \mathrm{C} / \mathrm{min}$ up to $700{ }^{\circ} \mathrm{C}$ in a nitrogen atmosphere). The fractured surfaces of the epoxy composite tensile samples were morphologically characterized via scanning electron microscopy (SEM-EVO LS25, Zeiss). Samples for transmission electron microscopy (TEM) were prepared via ultramicrotomy (Leica Ultracut E) with a Diatome $45^{\circ}$ diamond knife (section thickness of $\sim 80 \mathrm{~nm}$ ) and characterized with a FEI Tecnai T12, microscope. Differential scanning calorimetry (DSC-Perkin-Elmer DSC7, $10{ }^{\circ} \mathrm{C} / \mathrm{min}$ up to $120^{\circ} \mathrm{C}$,) was used to determine the glass transition temperature $\left(T_{g}\right)$ of each system, while tensile testing (Tinius Olsen H25KS Tensometer) using a strain rate of $1 \mathrm{~mm} / \mathrm{min}$ on dumbbell-shaped 
samples ( $4 \mathrm{~mm}$ thick, as specified by the ASTM D638$02 \mathrm{~A}$ ) was conducted to determine variations in tensile properties. DC electrical conductivity measurements were performed using a Keithley 6517B system together with a 8009-resistivity fixture (applied voltage $100 \mathrm{~V}$, film samples $200 \mu \mathrm{m}$ in thickness). Thermal conductivity was determined using a steady-state technique at ambient temperature (details of the in-house built apparatus can be found in [21]); the samples were disk-shaped, with a thickness of $3 \mathrm{~mm}$ and a diameter of $50 \mathrm{~mm}$.

\section{Results and discussion}

\subsection{Powder surface chemistry}

Since a key element of this study concerns the chemistry of $\mathrm{eGO}$ and $\mathrm{mGO}$ and the associated degrees of structural disorder, these aspects will first be presented in terms of Raman spectroscopy, XPS and TGA (Fig. 1).

The Raman spectra of eGO and $\mathrm{mGO}$ are compared in Fig. 1a. In this, three characteristic bands can be seen which correspond respectively to $D, G$ and $2 D$. The $G$ band
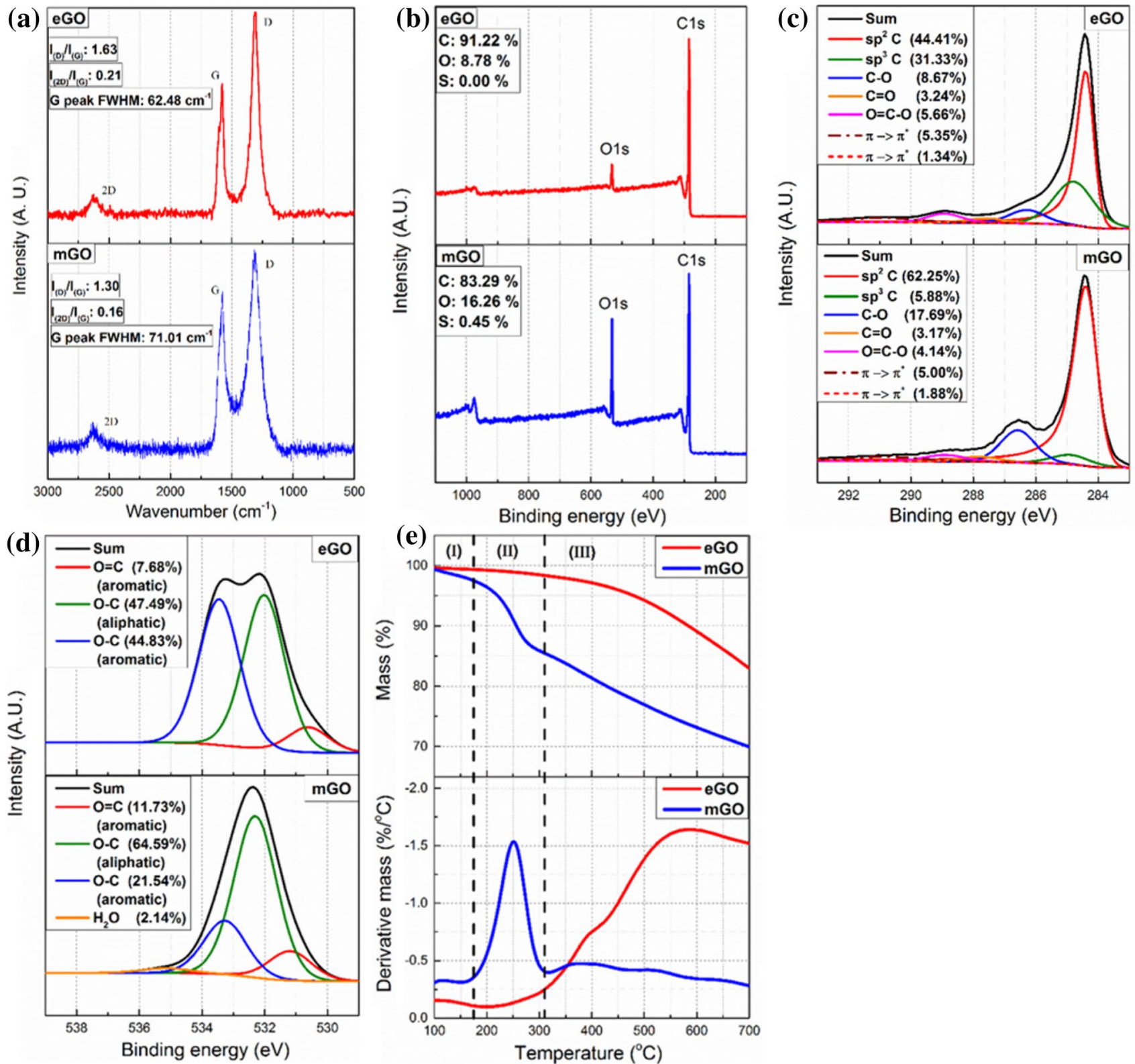

Fig. 1 a Raman spectra, b XPS survey, c C1s core level, d O1s core level, e TGA (upper) and DTG (lower) plots of eGO and mGO 
represents the in-phase, graphitic vibrations of the $\mathrm{sp}^{2}$ carbon lattice, the $D$ band is related to the induced disorder $\left(\mathrm{sp}^{3}\right.$ hybridization) derived from powder processing, while the $2 \mathrm{D}$ band stems from the stacking order of crystalline graphite [29]. The location of the $G$ band is the same for the two samples $\left(1576 \mathrm{~cm}^{-1}\right)$, however, the full width at half maximum (FWHM) value of this band is larger for $\mathrm{mGO}$ compared with eGO (see Fig. 1a insets), indicating a more oxygenated surface [24] for the former. However, the eGO is characterised by an increased $I_{(D)} / I_{(G)}$ ratio, $I_{(X)}$ represents the peak height of the $X$ Raman band [30]), compared to the $\mathrm{mGO}$, which indicates higher defect content for eGO. Previous work [31] on the effect of thermal processing of graphitic compounds revealed a progressive increase in the $I_{(D)} I_{(G)}$ ratio up to $1000{ }^{\circ} \mathrm{C}$, a phenomenon attributed to the introduction of carbon-based defects. Furthermore, it has been discussed elsewhere [32] that increased $I_{(D)} / I_{(G)}$ values are associated with smaller domains of $\mathrm{sp}^{2}$ carbon atoms and/or larger fractions of graphitic edges. Since the eGO has been produced by processes including thermal shock at temperatures similar to the abovementioned [33], it is assumed that the increased $I_{(D)} / I_{(G)}$ ratio it displays is ascribed to thermally induced carbon defects. Moreover, a comparison of $I_{(2 D)} I_{(G)}$ ratios reveals that the $\mathrm{mGO}$ displays increased stacking disorder (lower $I_{(2 D)} / I_{(G)}$ ratio [24]) compared with the eGO.

Figure $1 \mathrm{~b}$ shows XPS survey scans of the $\mathrm{eGO}$ and $\mathrm{mGO}$ powders, together with derived elemental ratios in the insets. The eGO is characterized by a lower oxygen content than the $\mathrm{mGO}$, which aligns with the Raman $\mathrm{G}$ band FWHM values described above. The small sulfur content of the $\mathrm{mGO}$ is attributed to sulfates generated during the oxidation process [28].

Figure $1 \mathrm{c}$ contains deconvoluted $\mathrm{C} 1 \mathrm{~s}$ data, together with the assigned carbon bonding. From this, it is evident that for both powders, the C1s peak is described in terms of seven contributions, which are related to $\mathrm{sp}^{2}$ and $\mathrm{sp}^{3}$ hybridized carbon (284.4 and $285.04 \mathrm{eV}$, respectively), C $-\mathrm{O}$ bonds (286.72 eV) from hydroxyl and/or epoxide groups, $\mathrm{C}=\mathrm{O}(288 \mathrm{eV})$ and $\mathrm{O}=\mathrm{C}-\mathrm{O}$ bonds from carboxyls $(289.06 \mathrm{eV})$, as well as two $\pi \rightarrow \pi^{*}$ transitions (290.85 and $293.9 \mathrm{eV}$ ). The eGO contains a relatively larger concentration of the peripheral carboxylic groups, while the $\mathrm{mGO}$ shows increased basal $\mathrm{C}-\mathrm{O}$ bonding. Evidently, the $\mathrm{sp}^{3}$ carbon-related peak is quite strong in eGO, despite its lower oxygen content, which is associated with the presence of hydrocarbon-based defects such as anthracene [34]; such species can be present even after oxygen removal through thermal reduction [11]. The latter aligns well with the $I_{(D)} / I_{(G)}$ intensity in the Raman spectra described above, indicating that the disorder of eGO is mainly attributed to the presence of carbon defects and not oxygen. Furthermore, both powders display equivalent $\pi \rightarrow \pi^{*}$ transitions, which is qualitatively connected to the system's electrical conductivity [35], thereby implying that $\mathrm{mGO}$ and eGO are characterized by similar intrinsic electrical properties.

Figure $1 \mathrm{~d}$ shows deconvoluted $\mathrm{O} 1 \mathrm{~s}$ peak data together with the assigned oxygen bonding. Both samples exhibit three main peaks attributed to: aromatic $\mathrm{O}=\mathrm{C}$ (530-531 eV), aliphatic O-C (532 eV) and aromatic O-C $(533 \mathrm{eV})$, with the $\mathrm{mGO}$ also showing another peak at $535 \mathrm{eV}$, attributable to adsorbed water molecules [36]. From this, it appears that the $\mathrm{mGO}$ is characterised by an increased intensity of aliphatic oxygen bonds compared with the eGO, which stems from the dominant oxygenbased functional groups. Conversely, the eGO displays a considerable aromatic character, which is attributed to the carbon-based defects mentioned above.

Figure 1e presents TGA data obtained from eGO and $\mathrm{mGO}$. The decomposition of the latter system is considered in terms of three weight loss processes: from 100 to $175^{\circ} \mathrm{C}$ (region I); from 175 to $310^{\circ} \mathrm{C}$ (region II); from 310 to $700^{\circ} \mathrm{C}$ (region III). These are ascribed to removal of (I) water molecules, (II) labile oxygen-based groups and (III) stable oxygen-based groups [28]. The derivative mass loss (DTG) plot of mGO suggests that the dominant process corresponds to region II, which represents a total mass loss of $\sim 12 \mathrm{wt} \%$. This region has previously been linked to the aliphatic groups mentioned above [36], aligning with the notion that $\mathrm{mGO}$ is dominated by singly bonded basal plane functionalities. In contrast, the eGO displays minimal mass loss in regions I and II, aligning with the absence of water and the reduced intensity of basal oxygen-based groups. Nevertheless, both systems show a similar progressive mass loss in region III, which has been related to peripheral stable $\mathrm{C}=\mathrm{O}$ bonds, indicating equivalently oxygenated peripheries. This process is asymmetric (showing various features in the DTG plot), an effect connected to the presence of antagonistic processes related to $C=O$ groups, as stated elsewhere [36].

\subsection{Morphology of epoxy composites}

SEM images showing the surface of fractured tensile epoxy samples are presented in Fig. 2. Evidently, the inclusion of $\mathrm{mGO}$ or eGO alters the crack propagation pattern of the epoxy matrix, resulting in rougher fractured surfaces compared to the unfilled system. Since the surface textures presented in Fig. 2b, c appear comparable, this effect is largely independent of the filler's precise surface chemistry, as claimed elsewhere [18].

However, the distribution of $\mathrm{mGO}$ within the matrix is different from that of eGO, as can be seen in Fig. 3. More specifically, the eGO is not distributed homogeneously, resulting in "densely populated" regions, which seemingly act as crack initiators (circled in red in Fig. 3a, c). 


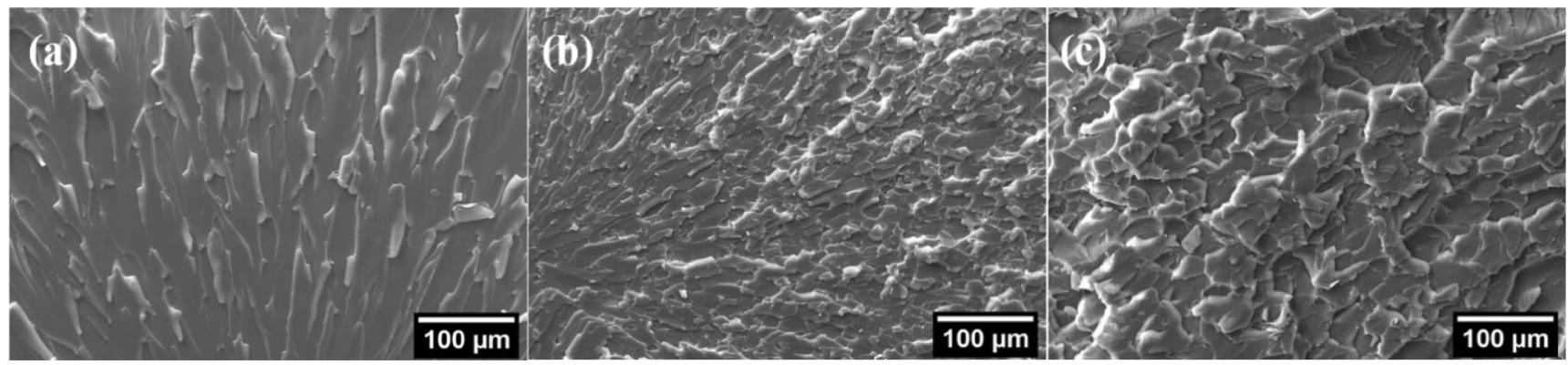

Fig. 2 Crack propagation pattern as taken from SEM imaging of: a unfilled, $\mathbf{b}$ eGO-filled and $\mathbf{c}$ mGO-filled epoxy; the filler contents for the two latter are 0.26 vol. $\%$

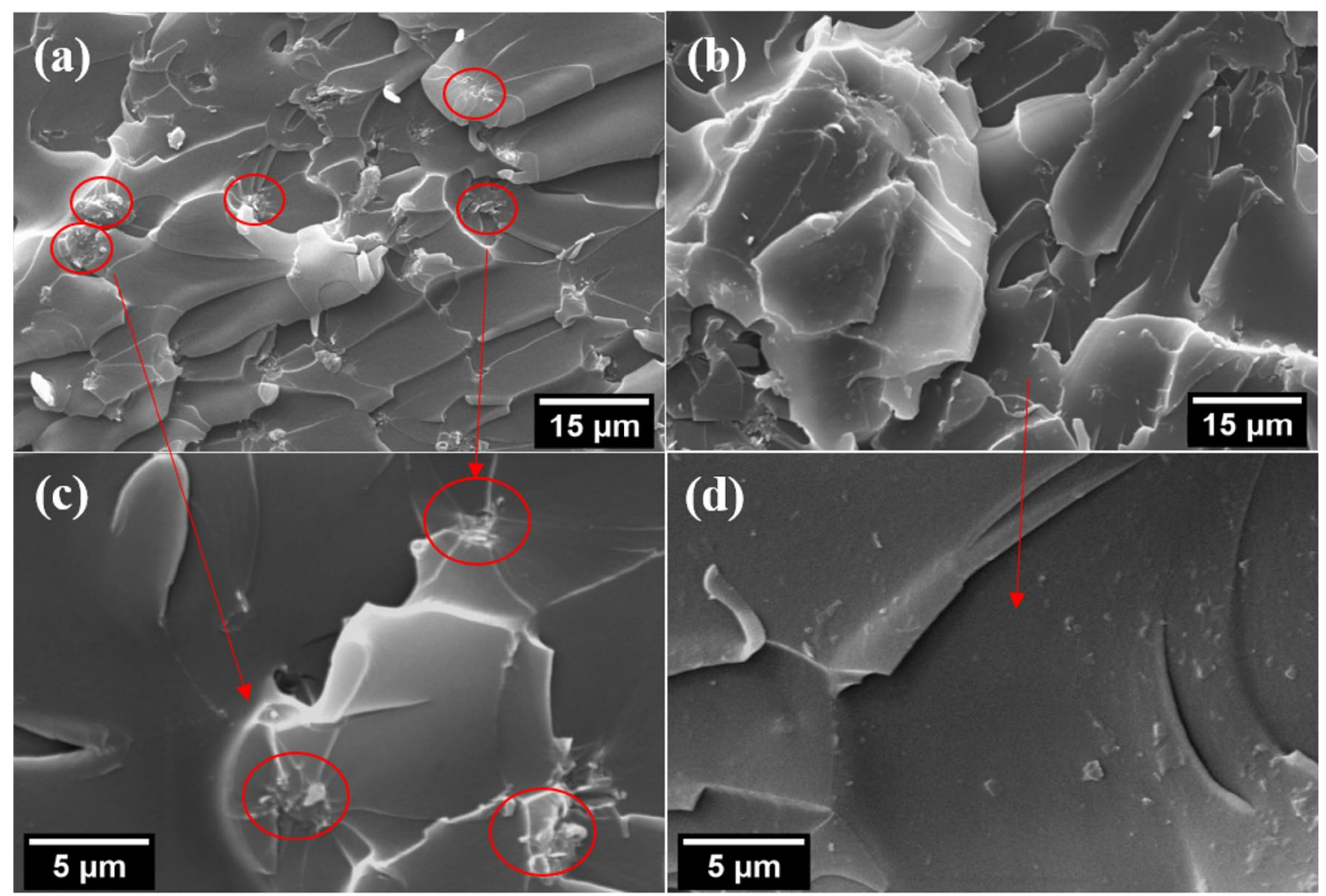

Fig. 3 SEM images of epoxy filled with 0.26 vol.\% of: $\mathbf{a}, \mathbf{c}$ eGO and $\mathbf{b}, \mathbf{d} \mathrm{mGO}$

Comparable features cannot be seen in Fig. 3b, d, implying that the $\mathrm{mGO}$ is more uniformly distributed within the matrix.

While it is possible clearly to distinguish larger eGO clusters in the case of systems based upon this filler, the SEM images are less informative concerning the dispersion of $\mathrm{mGO}$ and, as such, complementary TEM data are presented in Fig. 4. Comparison of these micrographs reveals that the mGO-filled systems (Fig. 4a, b) contain a range of exfoliated entities and small regions of stacked platelets (circled in red). In contrast, the eGO appears, generally, to be less well dispersed and to form larger clusters (Fig. 4c, d).

\subsection{Properties of epoxy composites}

The overall property envelope of the $\mathrm{mGO}$ - and eGOfilled epoxy nanocomposites, in terms of $T_{g}$, tensile performance, electrical and thermal conductivity will now be contrasted (Fig. 5). The maximum filler contents may vary depending on the filler and the characterization method, in order best to portray the relevant behaviour. 

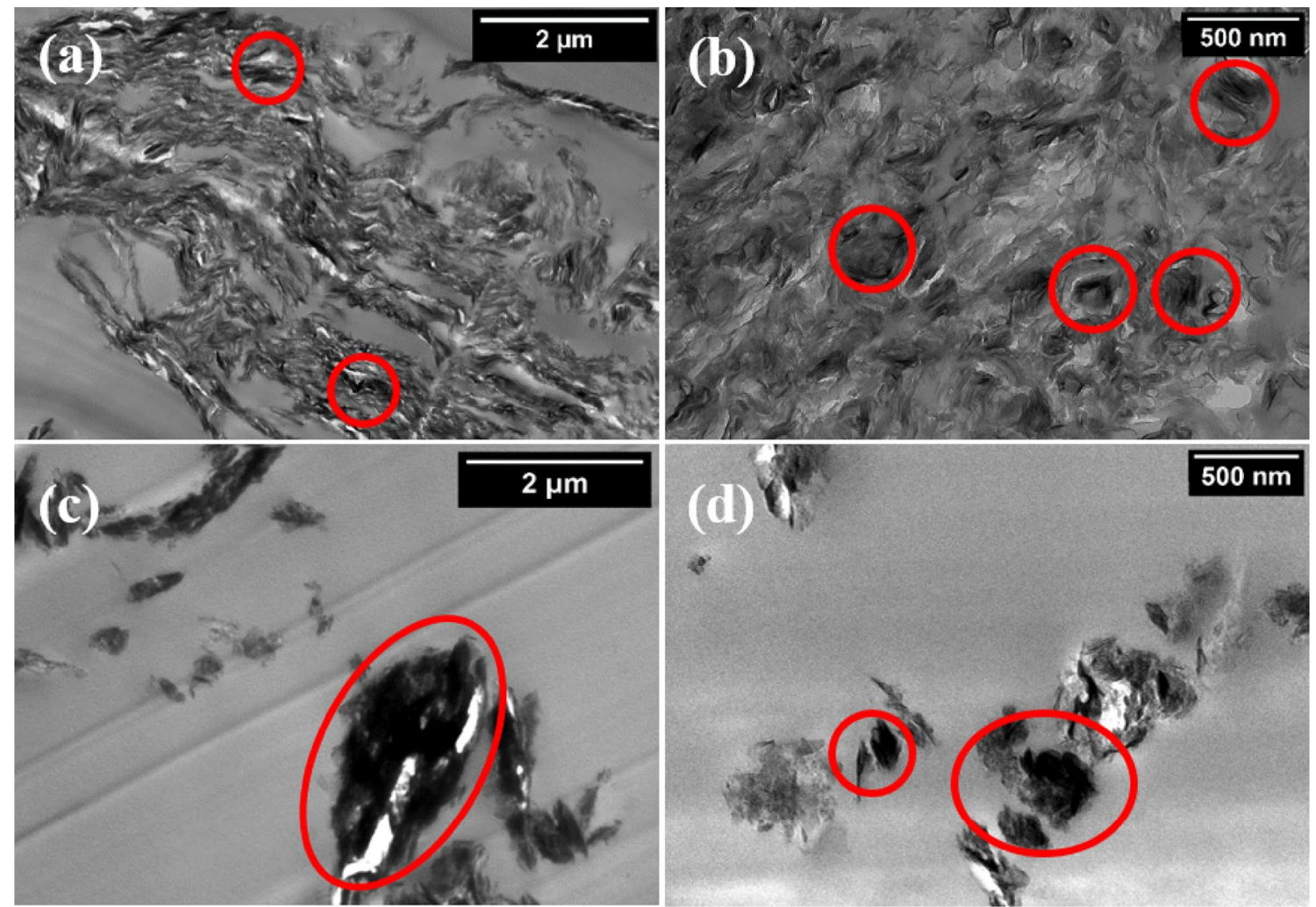

Fig. 4 TEM images of epoxy resin filled with 1 vol.\% of: $\mathbf{a}, \mathbf{b}$ mGO and $\mathbf{c}, \mathbf{d}$ eGO

Figure $5 \mathrm{a}$ shows the effect of eGO and $\mathrm{mGO}$ weight/ volume contents on the $T_{g}$, of the associated epoxybased composites. The volume percentage was calculated [14] from the weight percentage assuming density values for the matrix $\left(\rho_{m}\right)$ and filler $\left(\rho_{f}\right)$ of $1.16 \mathrm{~g} / \mathrm{cm}^{3}$ and $2.2 \mathrm{~g} / \mathrm{cm}^{3}$ [16], respectively. From this, it can be seen that the inclusion of $\mathrm{mGO}$, results in an initial $T_{g}$ increase, followed by a sharp $T_{g}$ decrease, which is a consequence of the increase in the concentration of reactive functional groups $[18,28]$. The fact that the eGO did not result in a $T_{g}$ drop, aligns with: (1) the reduced amount of oxygenbased functionalities and (2) the relatively non-reactive characteristics of its dominant functionalities (carboxyls) with the epoxy.

Figure $5 \mathrm{~b}$ shows the effect of $\mathrm{mGO}$ and $\mathrm{eGO}$ on the elastic modulus of the system, from which it is evident that both fillers result in a slight increase in this parameter. Both fillers contain relatively low oxygen contents, which has been demonstrated elsewhere [37] to result in lesser mechanical enhancements when compared with highly oxygenated GO species. Nevertheless, the fact that no detrimental effects on the modulus values were observed (an effect attributed to altered stoichiometry [18]) confirms that neither mGO nor eGO materially affect the epoxy curing reaction at the filler contents considered here.
Comparing the tensile strength of mGO- and eGOfilled epoxy samples (Fig. 5c) it can be seen that the latter display a rapidly deteriorating performance, while this is not the case for the former, which maintain the strength at higher filler fractions. Since there is no adverse effect on the epoxy stoichiometry (this would manifest itself in major changes in $T_{g}$ ), the impaired tensile strength is most likely related the agglomeration or poor particle distribution [18], as seen in the SEM images shown above, suggesting that crack initiation occurs from the poorly distributed eGO. Therefore, we suggest that the observed behavior is directly linked to the surface chemistry of each powder, which results in either fine ( $\mathrm{mGO}$ ) or poor distribution/crack initiation (eGO) within the matrix.

The effect of filler content on electrical conductivity is shown in Fig. 5 d. Inclusion of $\mathrm{mGO}$ results in a sharp increase in conductivity at low loading levels and a clear percolation threshold at $\sim 0.5 \mathrm{vol} . \%$. In contrast, at the same filler content, the eGO-filled systems are characterized by markedly lower conductivity values; in these systems, the variation with composition is much more gradual showing a progressive increase up to $~ 7$ vol.\% and a mild increase at higher filler contents. Nevertheless, the maximum observed conductivity for both systems is of a comparable order of magnitude. Percolation behavior 


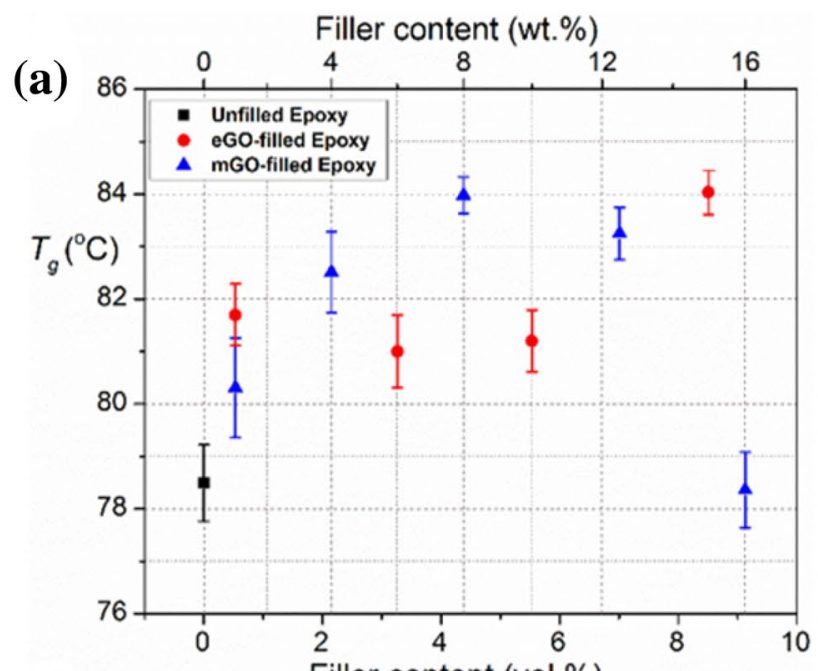

(c)
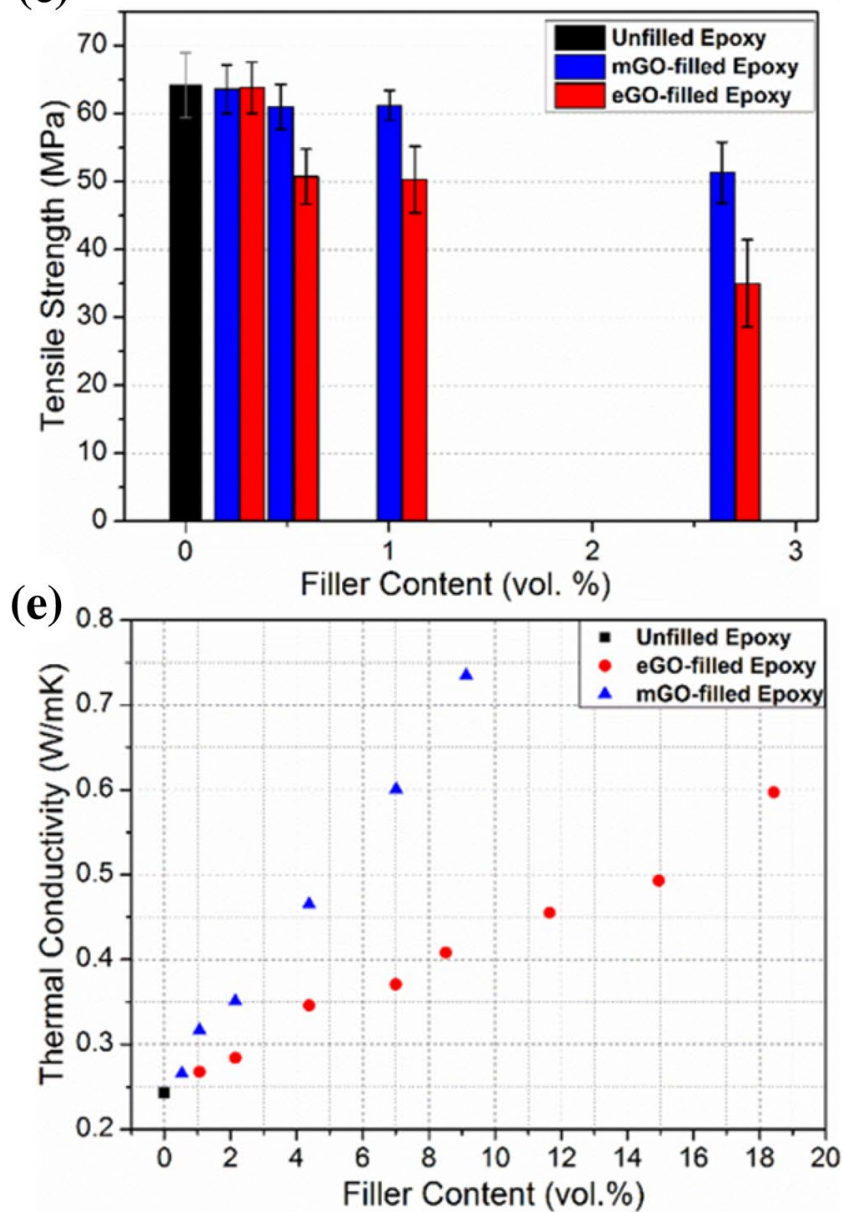

(b)

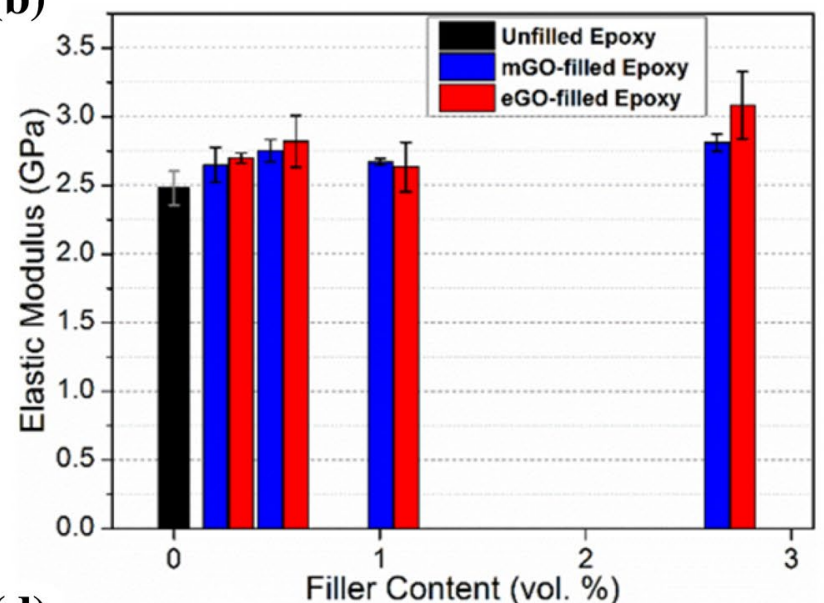

(d)

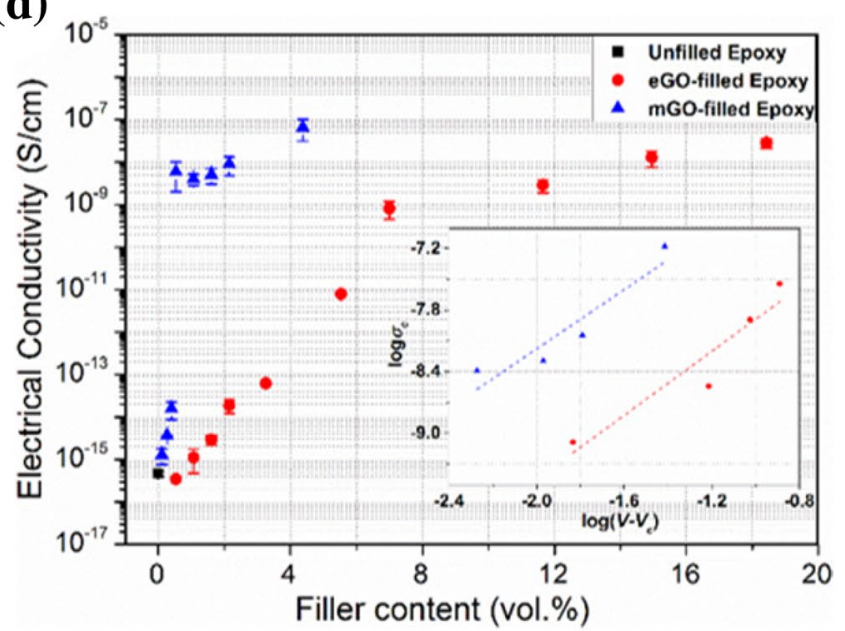

Fig. 5 Examined properties of the unfilled, mGO-filled and eGO-filled epoxy systems. a $T_{g}$ with the respective weight/volume contents, $\mathbf{b}$ elastic modulus, $\mathbf{c}$ tensile strength, $\mathbf{d}$ electrical conductivity (Inset: $\log -\log$ plot) and $\mathbf{e}$ thermal conductivity

has been discussed elsewhere [38, 39] and is typically described by:

$\sigma_{c}=\sigma_{f}\left(V_{f}-V_{c}\right)^{t}$ where $\sigma_{c}$ and $\sigma_{f}$ are the electrical conductivity of the composite and the filler respectively, $t$ is a constant, $V_{f}$ is the filler content and $V_{c}$ is the percolation threshold. Fitting 
of Eq. 1 to the experimental data (inset of Fig. $5 d$ ) leads to values of:

- $V_{c}=0.53 \%, \sigma_{f}=10^{-(5.29 \pm 0.72)} \mathrm{S} / \mathrm{cm}$ and $t=1.44 \pm 0.38$ for $\mathrm{mGO}$

- $V_{c}=5.53 \%, \sigma_{f}=10^{-(6.33 \pm 0.48)} \mathrm{S} / \mathrm{cm}$ and $t=1.56 \pm 0.37$ for eGO.

Comparison of these results indicates similar intrinsic properties of the two fillers, aligning with the equivalent $\pi \rightarrow \pi^{*}$ shakeup shown above. The significantly different percolation behavior of the respective epoxy composites is therefore, again, attributable to their divergent matrix compatibility and the consequent dispersion behavior, as seen in the SEM and TEM images above. The improved epoxy/mGO interactions facilitate the formation of percolating paths, while the reduced matrix compatibility of the eGO manifests itself increased agglomeration and a markedly higher percolation threshold.

Finally, thermal conductivity values and their dependency on the mGO and eGO content are presented in Fig. 5e. From this, it appears that the incorporation of both nanofillers linearly increases the thermal conductivity of the system, albeit at different rates. The maximum achieved value with $\mathrm{mGO}$ was a $200 \%$ increase, which occurred at 9.13 vol.\% (16 wt\%), while a maximum increase of $150 \%$ was achieved at the much higher loading level of $18 \mathrm{vol} \%$ (30 wt\%) of eGO. This clearly aligns with the improved matrix bonding that the $\mathrm{mGO}$ shows (see DSC data) which represents one of the most beneficial strategies in increasing the thermal conductivity of composites [40]. Another possible parameter affecting the reduced thermal conductivity values for eGO is the decreased aspect ratio [41] due to its limited compatibility, as shown in the TEM images.

Overall, comparison of the above results clearly indicates a critical transition from low (eGO) to moderately low (mGO) oxygen content. Furthermore, the importance not of oxygen content per se, but basal plane oxygenation is underlined, since peripheral oxygenation appears relatively ineffective in promoting preferential filler/matrix interactions and/or higher levels of dispersion.

\section{Conclusions}

Structural and chemical characterization of eGO and mGO was undertaken in terms of Raman, XPS and TGA analysis. It is revealed that both systems show similar degree of peripheral oxidation, while mGO additionally shows basal-plane decoration. The moderate oxidation route appears to be beneficial for the attachment of oxygen-based groups, without furtherly damaging the undecorated graphitic lattice, while the processing used in the production of eGO results in increased carbon defects. Those structural/chemical divergences strongly affect the morphology and properties of the related epoxy-based composites. The mGO-filled epoxy was characterized by enhanced filler/matrix bonding, which impaired the $T_{g}$ values at high filler contents, while eGO remained unreactive. Furthermore, the eGO-filled epoxy showed rapidly deteriorating tensile strength when compared with mGOfilled samples due to limited filler compatibility, aggregation and consequent crack initiation, as revealed by SEM and TEM imaging. Incorporation of $\mathrm{mGO}$ into the epoxy resulted in a low and sharp percolation threshold, while addition of eGO leads to a gradual increase in electrical conductivity. Nevertheless, both fillers resulted in similar maximum electrical conductivity values. Furthermore, the $\mathrm{mGO} / \mathrm{epoxy}$ bonding and compatibility served to significantly enhance the thermal conductivity values of the respective composites compared with the equivalent eGO-filled ones. Thus, the structural/chemical distinctiveness revealed by $\mathrm{mGO}$ and eGO, as well as the linkage to the respective nanocomposite properties creates a scope for optimized electrical and thermal performance, without compromised mechanical properties.

Acknowledgements This work was supported by the European Union's Horizon 2020 research and innovation programme under the Marie Sklodowska-Curie Grant agreement [No 642771]. The Authors would like to acknowledge the help of Marc Walker and the use of Warwick Photoemission Facility within the Departments of Physics and Chemistry, at the University of Warwick. The authors would also like to thank E. Senis for the SEM images and Dr. S. Virtanen for part of the TEM images.

\section{Compliance with ethical standards}

Conflict of interest The authors declare that they have no conflict of interest.

Open Access This article is distributed under the terms of the Creative Commons Attribution 4.0 International License (http://creativeco mmons.org/licenses/by/4.0/), which permits unrestricted use, distribution, and reproduction in any medium, provided you give appropriate credit to the original author(s) and the source, provide a link to the Creative Commons license, and indicate if changes were made.

\section{References}

1. Paul DR, Robeson LM (2008) Polymer nanotechnology: nanocomposites. Polymer (Guildf) 49:3187-3204. https://doi. org/10.1016/j.polymer.2008.04.017

2. Pavlidou S, Papaspyrides CD (2008) A review on polymer-layered silicate nanocomposites. Prog Polym Sci 33:1119-1198. https:// doi.org/10.1016/j.progpolymsci.2008.07.008 
3. Zanetti $M$, Bracco $P$, Costa $L$ (2004) Thermal degradation behaviour of PE/clay nanocomposites. Polym Degrad Stab 85:657-665. https://doi.org/10.1016/j.polymdegradstab.2004.03.005

4. Huang Y, Ellingford C, Bowen C et al (2019) Tailoring the electrical and thermal conductivity of multi-component and multi-phase polymer composites. Int Mater Rev. https://doi. org/10.1080/09506608.2019.1582180

5. Jager K-M, Lindbom L (2005) The continuing evolution of semiconductor materials for power cable applications. IEEE Electr Insul Mag 21:20-34. https://doi.org/10.1109/MEl.2005.1389267

6. El-Tantawy F, Kamada K, Ohnabe H (2002) In situ network structure, electrical and thermal properties of conductive epoxy resincarbon black composites for electrical heater applications. Mater Lett 56:112-126. https://doi.org/10.1016/S0167-577X(02)00401-9

7. Debelak B, Lafdi K (2007) Use of exfoliated graphite filler to enhance polymer physical properties. Carbon NY 45:1727-1734. https://doi.org/10.1016/j.carbon.2007.05.010

8. Gojny FH, Wichmann MHG, Fiedler B et al (2006) Evaluation and identification of electrical and thermal conduction mechanisms in carbon nanotube/epoxy composites. Polymer (Guildf) 47:20362045. https://doi.org/10.1016/j.polymer.2006.01.029

9. Jang BZ, Zhamu A (2008) Processing of nanographene platelets (NGPs) and NGP nanocomposites: a review. J Mater Sci 43:50925101. https://doi.org/10.1007/s10853-008-2755-2

10. Dreyer DR, Todd AD, Bielawski CW (2014) Harnessing the chemistry of graphene oxide. Chem Soc Rev 43:5288-5301. https://doi. org/10.1039/c4cs00060a

11. Li X, Biswas S, Drzal LT (2013) High temperature vacuum annealing and hydrogenation modification of exfoliated graphite nanoplatelets. J Eng (United States). https://doi.org/10.1155/2013/638576

12. Papageorgiou DG, Kinloch IA, Young RJ (2017) Mechanical properties of graphene and graphene-based nanocomposites. Prog Mater Sci 90:75-127. https://doi.org/10.1016/j.pmats ci.2017.07.004

13. Lerf A, He H, Forster M, Klinowski J (1998) Structure of graphite oxide revisited. J Phys Chem B 102:4477-4482. https://doi. org/10.1021/jp9731821

14. Li Z, Chu J, Yang C et al (2018) Effect of functional groups on the agglomeration of graphene in nanocomposites. Compos Sci Technol 163:116-122. https://doi.org/10.1016/j.compscitec h.2018.05.016

15. Ma J, Meng Q, Zaman I et al (2014) Development of polymer composites using modified, high-structural integrity graphene platelets. Compos Sci Technol 91:82-90. https://doi.org/10.1016/j. compscitech.2013.11.017

16. Stankovich S, Dikin DA, Piner RD et al (2007) Synthesis of graphene-based nanosheets via chemical reduction of exfoliated graphite oxide. Carbon N Y 45:1558-1565. https://doi. org/10.1016/j.carbon.2007.02.034

17. MuX, Wu X, Zhang T et al (2014) Thermal transport in graphene oxide-from ballistic extreme to amorphous limit. Sci Rep 4:3909. https://doi.org/10.1038/srep03909

18. Vryonis O, Virtanen STH, Andritsch T et al (2019) Understanding the cross-linking reactions in highly oxidized graphene/epoxy nanocomposite systems. J Mater Sci 54:3035-3051. https://doi. org/10.1007/s10853-018-3076-8

19. Erdely A, Dahm M, Chen BT et al (2013) Carbon nanotube dosimetry: from workplace exposure assessment to inhalation toxicology. Part Fibre Toxicol 10:1-14. https://doi. org/10.1186/1743-8977-10-53

20. Mishnaevsky L, Branner K, Petersen HN et al (2017) Materials for wind turbine blades: an overview. Materials (Basel) 10:1-24. https ://doi.org/10.3390/ma10111285

21. Senis EC, Golosnoy IO, Dulieu-Barton JM, Thomsen OT (2019) Enhancement of the electrical and thermal properties of unidirectional carbon fibre/epoxy laminates through the addition of graphene oxide. J Mater Sci 54:8955-8970. https:// doi.org/10.1007/s10853-019-03522-8

22. Gagné $M$, Therriault $D$ (2014) Lightning strike protection of composites. Prog Aerosp Sci 64:1-16

23. Soutis C (2005) Fibre reinforced composites in aircraft construction. Prog Aerosp Sci 41:143-151

24. Krishnamoorthy K, Veerapandian M, Yun K, Kim SJ (2013) The chemical and structural analysis of graphene oxide with different degrees of oxidation. Carbon N Y 53:38-49. https://doi. org/10.1016/j.carbon.2012.10.013

25. Guerrero-Contreras J, Caballero-Briones F (2015) Graphene oxide powders with different oxidation degree, prepared by synthesis variations of the hummers method. Mater Chem Phys 153:209220. https://doi.org/10.1016/j.matchemphys.2015.01.005

26. Shen $\mathrm{L}$, Zhang L, Wang K et al (2018) Analysis of oxidation degree of graphite oxide and chemical structure of corresponding reduced graphite oxide by selecting different-sized original graphite. RSC Adv 8:17209-17217. https://doi.org/10.1039/c8ra01486h

27. Chen CH, Yang SW, Chuang MC et al (2015) Towards the continuous production of high crystallinity graphene via electrochemical exfoliation with molecular in situ encapsulation. Nanoscale 7:15362-15373. https://doi.org/10.1039/c5nr03669k

28. Vryonis O, Andritsch T, Vaughan AS, Lewin PL (2019) An alternative synthesis route to graphene oxide: influence of surface chemistry on charge transport in epoxy-based composites. J Mater Sci 54:8302-8318. https://doi.org/10.1007/s10853-019-03477-w

29. Esmaeili A, Entezari MH (2014) Facile and fast synthesis of graphene oxide nanosheets via bath ultrasonic irradiation. J Colloid Interface Sci 432:19-25. https://doi.org/10.1016/j.jcis.2014.06.055

30. Ferrari AC, Robertson J (2000) Interpretation of Raman spectra of disordered and amorphous carbon. Phys Rev B 61:95-107

31. Bernard S, Beyssac O, Benzerara K et al (2010) XANES, Raman and XRD study of anthracene-based cokes and saccharose-based chars submitted to high-temperature pyrolysis. Carbon N Y 48:2506-2516. https://doi.org/10.1016/j.carbon.2010.03.024

32. Bo Z, Shuai $X$, Mao $S$ et al (2014) Green preparation of reduced graphene oxide for sensing and energy storage applications. Sci Rep. https://doi.org/10.1038/srep04684

33. Yasmin A, Luo JJ, Daniel IM (2006) Processing of expanded graphite reinforced polymer nanocomposites. Compos Sci Technol 66:1179-1186. https://doi.org/10.1016/j.compscitech.2005.10.014

34. Estrade-Szwarckopf H (2004) XPS photoemission in carbonaceous materials: a "defect" peak beside the graphitic asymmetric peak. Carbon N Y 42:1713-1721. https://doi.org/10.1016/j.carbo n.2004.03.005

35. Pantea D, Darmstadt H, Kaliaguine S, Roy C (2003) Electrical conductivity of conductive carbon blacks: influence of surface chemistry and topology. Appl Surf Sci 217:181-193. https://doi. org/10.1016/S0169-4332(03)00550-6

36. Ganguly A, Sharma S, Papakonstantinou P, Hamilton J (2011) Probing the thermal deoxygenation of graphene oxide using high-resolution in situ X-ray-based spectroscopies. J Phys Chem C 115:17009-17019

37. Li Z, Young RJ, Wang R et al (2013) The role of functional groups on graphene oxide in epoxy nanocomposites. Polymer (Guildf) 54:5821-5829. https://doi.org/10.1016/j.polymer.2013.08.026

38. Lux F (1993) Models proposed to explain the electrical conductivity of mixtures made of conductive and insulating materials. J Mater Sci 28:285-301. https://doi.org/10.1007/BF00357799

39. Nan C-W, Shen Y, Ma J (2010) Physical properties of composites near percolation. Annu Rev Mater Res 40:131-151. https://doi. org/10.1146/annurev-matsci-070909-104529

40. Nan C-W, Liu G, Lin Y, Li M (2004) Interface effect on thermal conductivity of carbon nanotube composites. Appl Phys Lett 85:35493551. https://doi.org/10.1063/1.1808874 
41. Li J, Ma PC, Chow WS et al (2007) Correlations between percolation threshold, dispersion state, and aspect ratio of carbon nanotubes. Adv Funct Mater 17:3207-3215. https://doi.org/10.1002/ adfm.200700065
Publisher's Note Springer Nature remains neutral with regard to jurisdictional claims in published maps and institutional affiliations. 